\title{
Mediação da informação e comunicação política no Facebook: desempenho do candidato Rui Palmeira à Prefeitura de Maceió em 2016
}

\section{Mediation of information and politics communication on the Facebook: performance of the candidate Rui Palmeira when running for mayor of Maceió City in 2016}

\author{
Ronaldo Ferreira Araujo ${ }^{1}$, Sarah Rúbia de Oliveira Santos ${ }^{1}$, Janyelle Mayara Bento ${ }^{1}$ \\ ${ }^{1}$ Universidade Federal de Alagoas - UFAL, Maceió, AL, Brasil
}

Autor para correspondência/Mail to: Ronaldo Ferreira Araujo (ronaldfa@gmail.com)

Recebido/Submitted: 15 Ago. 2017; Aceito/Approved: 22 Set. 2017

Copyright (c) 2017 Araujo, Santos \& Bento. Todo o conteúdo da Revista (incluindo-se instruções, política editorial e modelos) está sob uma licença Creative Commons Atribuição-NãoComercial-Compartilhalgual 3.0 Não Adaptada. Ao serem publicados por esta Revista, os artigos são de livre uso em ambientes educacionais, de pesquisa e não comerciais, com atribuição de autoria obrigatória. Mais informações em http://revistas.ufpr.br/atoz/about/submissions\#tcopyrightNotice.

\begin{abstract}
Resumo
Introdução: O crescente uso das redes sociais na internet por agentes políticos e eleitores configuram a entrada do país nos moldes de uma cultura digital participativa, constituindo-se uma esfera rica para o desenvolvimento de pesquisas sobre o desempenho dos candidatos em meio digital e a participação política do cidadão. O presente trabalho se propõe a verificar o desempenho no Facebook do candidato à Prefeitura de Maceió, Rui Palmeira nas eleições de 2016.

Método: A pesquisa tem caráter exploratório, de abordagem mista e cunho descritivo, com coleta de dados realizada pela ferramenta Netlytic e a análise por meio da categorização das publicações e compreensão das interações em sua página no Facebook.

Resultados: A maior parte das postagens realizadas diz respeito à Agenda do candidato (24,6\%), a Agradecimentos/Cumprimentos (16,7\%) e Propostas (15,8\%). Apesar disso, as postagens que tiveram maior interação dos eleitores são as de Cunho Pessoal, que compreenderam apenas $5,7 \%$ do total de postagens.

Conclusão: As mídias sociais começaram a ser ocupadas e tratadas com relevância no tocante ao cenário político, o que pode ser notado pela diversificação das categorias de postagens. O candidato em questão conseguiu compreender algumas premissas da Web 2.0 quanto à interação e colaboração, no entanto, é necessário destacar que há um longo caminho a percorrer no que tange à responsividade do candidato e interação direta com os eleitores via a ferramenta.
\end{abstract}

Palavras-chave: Mediação da informação; Redes sociais; Participação política

\begin{abstract}
Introduction: The Increasing use of social networks by political agents and voters sets a country into the mold of the digital participatory culture, constituting a rich field for the development of research on the performance of candidates in Digital Media and the citizen political participation. The study aims to verify the performance in Facebook of the Maceió city hall candidate, Rui Palmeira, in the elections of 2016.

Method: The research has an exploratory and descriptive character, based on mixed approach. The data collection was made using the Netlytic tool, followed by the analysis through the categorization of publications on his Facebook page, focusing on the interactions with the citizens.

Results: Most of the postings were related to the Agenda of the candidate (24.6\%) or Acknowledgments/Greetings (16.7\%), and Proposals (15.8\%). Nonetheless, the posts that have greater interaction of the citizens were those of Personal Issues, which comprised only $5.7 \%$ of the posts total. Conclusion: Social media, as it began to be occupied and understood as having relevance to the political scenario, can be shown by the diversification of the categories of facebook postings. The candidate was able to understand some of the premises of Web 2.0 regarding interaction and collaboration, however, it is necessary to point out that there is a long way to go in relation to the candidate's responsiveness and direct interaction with the voters using this social media tool.
\end{abstract}

Keywords: Information mediation; Social networks; Political participation

\section{INTRODUÇÃO}

As mídias e redes sociais no ambiente participativo e colaborativo da Web 2.0 possibilitam um espaço de trocas informacionais no qual os usuários são produtores e consumidores de conteúdos podendo criar e disseminar seu próprio conteúdo, circular e recombinar dados e informações de terceiros e interagirem entre si.

Por essa característica de criação e disseminação de conteúdo, Araújo (2016, p. 501), considera o crescente uso das mídias sociais por agentes políticos e eleitores como um marco da "entrada das eleições do país nos moldes de uma cultura digital participativa" e que esta se constitui como uma esfera rica para o desenvolvimento de pesquisas sobre o desempenho dos candidatos em meio digital e a participação política do cidadão. Para o autor, quando vistos no contexto das campanhas online esses novos ambientes digitais "possuem potencial democrático no estreitamento das relações entre os cidadãos e políticos por meio de uma mediação da informação expressa em uma comunicação dialógica" (Araújo, 2016, p. 501).

Após as campanhas eleitorais para Presidente dos Estados Unidos da América em 2008 e o uso perspicaz das mídias sociais pelo candidato Barack Obama e equipe no que diz respeito a sair do anonimato para a presidência, 
e construção de um perfil político sólido, nota-se o desenrolar de uma verdadeira revolução no que tange ao aspecto de marketing político na internet. Observa-se que as redes sociais na internet fomentaram novas formas de interação, entre candidato e os eleitores em potencial, auxiliadas pelas estratégias de marketing em um ambiente até então subutilizado para esta finalidade. Para Aggio (2011, p. 2) neste panorama que se desenha, "as campanhas superam as barreiras de seus websites e se lançam naqueles espaços online onde grande parte dos cidadãos que utiliza a internet constrói perfis, interage, produz e consome informações numa relação de envolvimento, compartilhamento e cooperação".

Nesse contexto, algumas pesquisas (Aggio, 2011; Barros, Bernardes, \& Sathler, 2016; Cervi \& Massuchin, 2011; C. L. S. Pereira, 2013; R. B. Silva, 2014) utilizaram as mídias sociais como ambiente de pesquisa para analisar o comportamento e desempenho de agentes políticos, focando ou em campanhas estaduais, presidenciais, em parlamentares da Câmara dos Deputados ou, ainda, em órgãos/partidos políticos e movimentos sociais.

Porém, muitos desses trabalhos têm como foco o Twitter e suas funcionalidades, além de analisar agentes políticos numa esfera mais ampla e abrangente do nosso sistema político. Pretende-se, aqui, realizar um estudo em caráter local, analisando o desempenho do candidato à Prefeitura de Maceió, Rui Soares Palmeira/PSDB, no Facebook, por meio da quantificação e categorização das publicações e dos números de interações nestas.

Nesse sentido, a Ciência da Informação (CI) tem muito a contribuir ao investigar as "ações de informação" (Araújo, 2014a) de candidatos e eleitores e verificar de que forma se dá a mediação da informação nas mídias sociais. De acordo com Almeida Júnior (2009, p. 92) a mediação da informação é "toda ação de interferência [...] direta ou indireta; consciente ou inconsciente; singular ou plural; individual ou coletiva; que propicia a apropriação de informação que satisfaça, plena ou parcialmente, uma necessidade informacional”.

Na mesma perspectiva Araújo (2014b) entende a mediação da informação como um processo de transferência da informação tendo em vista as necessidades de informação dos indivíduos. E para o autor, no contexto da comunicação política, os avanços tecnológicos, em especial da web social, têm ampliado a mediação da informação e possibilitado novas formas de engajamento cívico (Araújo, 2014b, p. 1457).

Por meio da Internet, Amaral (2010, p. 111) acredita que é possível promover tanto a participação do cidadão, "como também disponibilizar informações relevantes para a construção de sua cidadania, viabilizar a prestação de serviços públicos via computadores ou criar um espaço público que torne possível o debate entre cidadãos”.

O Facebook, então, ao possibilitar a criação de conteúdo, a divulgação de elementos de texto, elementos audiovisuais e links, além de permitir que o usuário interaja com os diversos conteúdos publicados por meio das ações de informação - comentários, curtidas e compartilhamentos - se configura como um dispositivo de mediação da informação, pois, por meio de suas ferramentas, interfere no processo de comunicação entre os usuários, inclusive da comunicação política.

\section{MATERIAL E MÉTODO}

Esta pesquisa tem caráter exploratório e abordagem mista e cunho descritivo. As pesquisas descritivas têm como objetivo primordial a "descrição das características de determinada população ou fenômeno ou, então, o estabelecimento de relações entre variáveis” (Gil, 2002, p. 42).

O ambiente de pesquisa é o Facebook, rede social criada por Mark Zuckerberg em 2004, que atualmente, é uma das redes sociais mais utilizadas no mundo. Zuckerberg (2017), em sua própria página no Facebook, estima que o número de usuários da rede social é de 1,9 bilhões em todo o mundo, sendo 1,2 bilhões ativos todos os dias. Destes, aproximadamente 99 milhões são brasileiros. Isto equivale a dizer que a cada dez brasileiros, oito utilizam a rede social (Cossetti, 2016). Dessa forma, este se constitui como um ambiente de possibilidades para a disseminação da informação política e, também, um meio para o desenvolvimento de estudos sobre a mediação dessa informação.

O candidato Rui Palmeira, 40 anos, é o atual prefeito reeleito da cidade de Maceió e disputou a campanha eleitoral em 2016 com outros seis candidatos, entre eles o ex-prefeito de Maceió, Cícero Almeida, e o deputado federal João Henrique Caldas (JHC). Ligado ao Partido da Social Democracia Brasileira (PSDB) e integrante da coligação 'Pra Frente Maceió', conquistou 46,86\% e 60,27\% dos votos disputados no $1^{\circ}$ e $2^{\circ}$ turno, respectivamente. O candidato foi selecionado para esse estudo por ter maior intenção de voto no $1^{\circ}$ turno, estando em primeiro lugar na pesquisa IBOPE (G1, 2016). Ao todo, foram analisadas 228 postagens com 121.530 curtidas, 5.930 compartilhamentos e 5.476 comentários, dentro do recorte temporal de 31 de agosto a 28 de setembro de 2016 .

Para a coleta de dados utilizou-se o Netlytic ${ }^{1}$, ferramenta online para análise de redes sociais e texto, que possibilita a coleta e análise de dados de mídias sociais. De acordo com Gruzd et al. (2017), a Netlytic foi criada por pesquisadores para pesquisadores, e com um design intituitivo que dispensa conhecimentos prévios em programação, além de possibilitar a coleta automatica de dados em redes sociais e realizar o resumo desses

${ }^{1}$ https://netlytic.org/ 
dados com base em planilhas, análise textual e de rede. Inicialmente, realizou-se o cadastro do dataset com o perfil oficial do candidato na mídia social Facebook e agendou-se o período de coleta. Após a coleta automática, exportou-se uma planilha CSV e converteu-se para o formato .xlsx para posterior triagem e análise dos resultados, posto que as postagens do candidato foram categorizadas de modo manual e em consenso entre os autores. Não se abordou o conteúdo dos comentários dos eleitores, mas coletaram-se os dados quantitativos sobre esse item, vinculando-os aos tipos de postagem realizados pelo candidato, com objetivo de verificar quais postagens despertaram maior interesse. Ao proceder a análise dos dados, visando quantificar e qualificar o desempenho do candidato Rui Palmeira em sua página no Facebook, utilizou-se como base as categorias elaboradas por Araújo e Pereira (2013), que tinham por finalidade caracterizar as postagens feitas pelos candidatos à prefeitura de Maceió em 2012 no Twitter e verificar quais entre elas produziam maior interatividade.

Em suas pesquisas, Aggio (2011), C. L. S. Pereira (2013), R. B. Silva (2014) e Barros et al. (2016) propuseram critérios ou categorias para analisar as formas de comunicação política em mídias digitais, como o Twitter e o Facebook, categorizando desde postagens de candidatos à prefeitura, passando por parlamentares cumprindo mandato, presidenciáveis e, ainda, partidos políticos. A partir destes trabalhos, foi possível alinhar um instrumento que permitisse uma análise aprofundada do material coletado.

A categorização se apresenta como um meio de organizar os dados para que, deles, possam ser tomadas decisões e tiradas conclusões. Segundo Gil (2002, p. 134) "isso requer a construção de um conjunto de categorias descritivas, que podem ser fundamentadas no referencial teórico da pesquisa”. Durante a análise, as categorias foram adaptadas para melhor representar o conteúdo analisado, seguindo a orientação de Fragoso, Recuero, e Amaral (2012, p. 83) por meio de "sistemática observação, comparação, classificação e análise de similaridades e dissimilaridades". Gil (2002, p. 134), aponta que nem sempre as “categorias podem ser definidas de imediato", e que a leitura dos dados pode influenciar na inclusão ou exclusão de categorias. Portanto, as categorias elaboradas e utilizadas na análise das postagens do candidato Rui Palmeira estão indicadas e descritas no Quadro 1.

\begin{tabular}{|l|l|}
\hline Categorias analíticas & Descrição \\
\hline Agenda do candidato & Atividades que o candidato participou, está participando ou participará. \\
\hline Agradecimento/Cumprimento & Mensagens que expressam gratidão ou cumprimento a terceiros. \\
\hline Apoio a terceiros & Demonstração de apoio a agentes políticos (e outros). \\
\hline Campanha negativa & Crítica/Ataques a adversários (e outros). \\
\hline Divulgação material de campanha & Mensagens em tom de propaganda ou marketing. \\
\hline Mobilização & Convocação para passeatas, carreatas, caminhadas etc. \\
\hline Pedido de voto & $\begin{array}{l}\text { Costuma acontecer quando se aproxima o dia das eleições, o candidato } \\
\text { evidencia o pedido "dia tal vote 45"ou "vote em mim" }\end{array}$ \\
\hline Postagem de cunho pessoal & $\begin{array}{l}\text { Reflexões, foto de família, amigos, publicação de status de algo que } \\
\text { esteja fazendo, lendo livro, ouvindo música etc. }\end{array}$ \\
\hline Proposta & Mensagens sobre o que o candidato pretende realizar caso eleito. \\
\hline Realizações & Feitos da vida política pregressa. \\
\hline Sondagem de opinião & Pesquisas de opinião sobre temas variados ou de intenção de voto \\
\hline Outros & Mensagens que não se enquadram nas categorias supracitadas \\
\hline
\end{tabular}

Quadro 1. Categorias elaboradas pelos pesquisadores para a análise do desempenho de agentes políticos Fonte: Dados da pesquisa (2016).

A partir das categorias foi possível verificar de que forma se deu o comportamento informacional e as estratégias de comunicação política do candidato Rui Palmeira frente à sua campanha eleitoral no Facebook.

\section{RESULTADOS}

No Facebook é possível que o usuário utilize diversos recursos para disseminar uma mensagem, podendo ser por meio de texto (status), pelo uso de materiais audiovisuais (imagens e vídeos), ou até mesmo links. Pelos dados coletados, pode-se quantificar qual o tipo de postagem mais utilizada pelo candidato Rui Palmeira (Tabela 1).

Pode-se observar que em 140, das 228 publicações na página do candidato, há a predominância de postagens com imagens. A utilização de imagens tem por objetivo chamar a atenção do usuário para o conteúdo da publicação (A. P. Silva \& Gonzales, 2016). Como as redes sociais possuem um aspecto dinâmico, em que muitas mensagens são compartilhadas ao mesmo tempo, o uso de imagens agiliza a comunicação.

Em seguida, em menor número, aparecem as postagens com vídeos. A maior parte dessas postagens pertencia à categoria de Divulgação de Material de Campanha e Propostas. Os programas que apresentavam propostas e 


\begin{tabular}{lrr}
\hline Tipo de postagem & Quantidade & $\%$ \\
\hline Imagens & 140 & 61,4 \\
Link & 12 & 5,3 \\
Status & 9 & 4,0 \\
Vídeos & 67 & 29,4 \\
\hline
\end{tabular}

Tabela 1. Quantificação por tipo de postagem utilizada pelo candidato Rui Palmeira Fonte: Dados da pesquisa (2016).

realizações do candidato e eram televisionadas, também eram transmitidas pela fanpage no Facebook. Dessa forma, o eleitor que não acompanhou a propaganda eleitoral pelo rádio ou televisão possuía um meio de se manter informado quanto a esse programa, tendo acesso ao mesmo conteúdo. Barros et al. (2016) apontam para o "poder de atração dos vídeos como mecanismos incitantes para o incremento da interação". As opções de links e status (apenas texto) são utilizadas em menor quantidade, embora as postagens com imagens e vídeos também possuam mensagens escritas.

Para averiguar o comportamento informacional do candidato Rui Palmeira, utilizou-se as categorias supracitadas e foram quantificadas no período eleitoral (Figura 1).

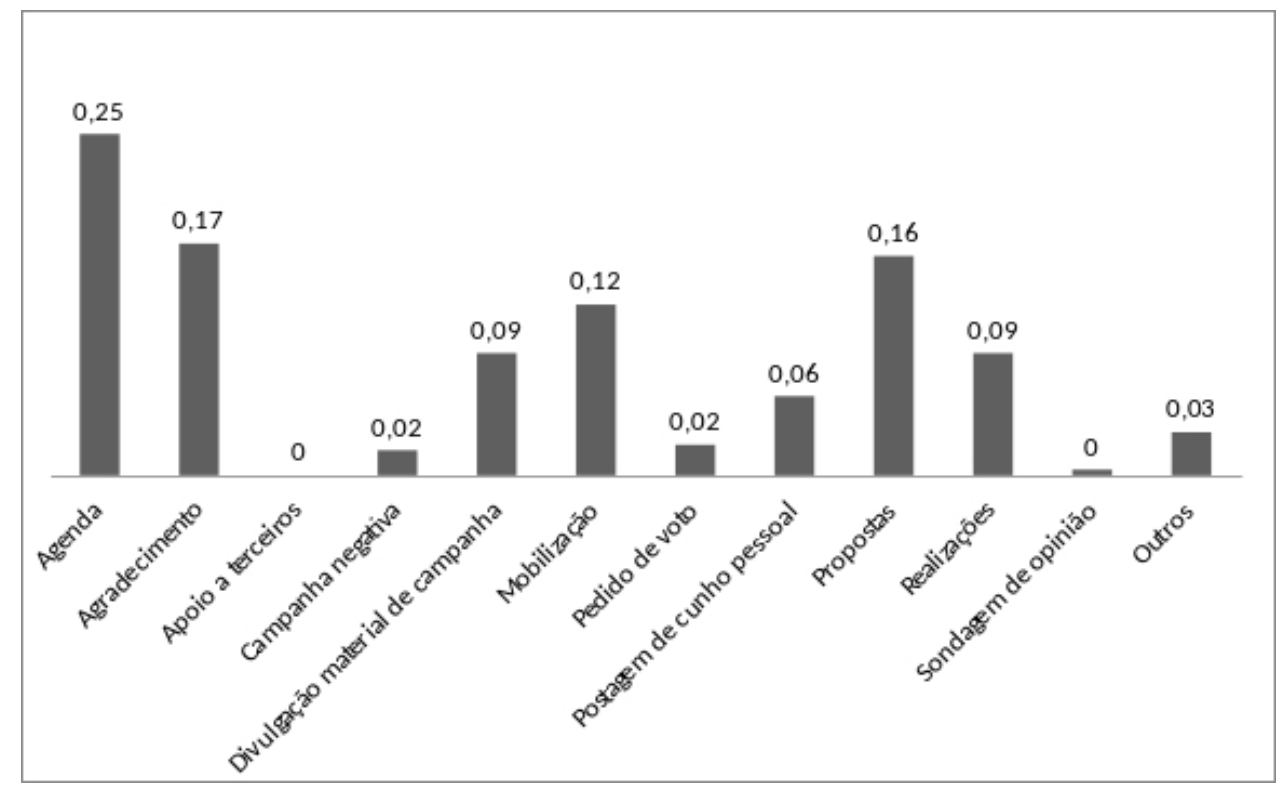

Figura 1. Quantificação por categorias - comportamento informacional do candidato Rui Palmeira Fonte: Dados da pesquisa (2016).

A maior quantidade de postagens realizadas pelo candidato diz respeito à sua Agenda (24,6\%), seguida da categoria de Agradecimento/Cumprimento (16,7\%) e, logo após, Propostas (15,8\%). Durante sua campanha, Rui Palmeira se mostrou bastante ativo ao participar de compromissos e divulgá-los em sua página, mantendo seu eleitorado a par das atividades que vinha desenvolvendo. Em Agradecimento/Cumprimento, era comum que suas publicações agradecerem pela participação dos eleitores em suas passeatas. Na categoria de Mobilização $(12,3 \%)$, ele convidava toda a população a participar dessas mesmas passeatas para fortalecer o movimento.

Referente à sua campanha, o candidato utilizou o espaço para divulgar suas Propostas, geralmente por meio de vídeos. Logo atrás, vêm as categorias de Divulgação de Material de Campanha (8,8\%) e Realizações $(8,8 \%)$. As Postagens de Cunho Pessoal (5,7\%) desempenharam papel importante na campanha por terem o objetivo de aproximar o público do candidato. Os tipos de publicações que tratavam de uma terceira pessoa ou da interação com o usuário possuíram menor número de postagens, a saber: Pedido de Voto (2,2\%), Campanha Negativa $(1,8 \%)$, Sondagem de Opinião $(0,4 \%)$ e Apoio a Terceiros ( $0 \%)$, evidenciando a verticalidade na comunicação, além do egocentrismo durante a campanha. $\mathrm{E}$, por fim, a categoria Outros $(3,1 \%)$ em que o conteúdo não aborda nem mensagens relacionadas à campanha, nem mensagens de cunho pessoal.

Assim, Rui Palmeira utilizou sua página como complemento para a campanha, divulgando informações pertinentes ao seu programa eleitoral. Entretanto, o candidato teve dificuldades em estimular seus eleitores na participação ativa em sua campanha, visto o caráter interativo da rede social, pelo menos no que diz respeito ao conteúdo das suas publicações.

Barros et al. (2016) observaram em seu trabalho que "no plano da interação entre os cidadãos o elemento característico predominante é a opção 'curtir’ ”. Recuero (2011, p. 119) afirma que 
o botão "curtir" parece ser percebido como uma forma de tomar parte na conversação sem precisar elaborar uma resposta. Toma-se parte, torna-se visível a participação, portanto, com um investimento mínimo, pois o ator não necessariamente precisa ler tudo o que foi dito. É uma forma de participar da conversação sinalizando que a mensagem foi recebida.

Por entender que o botão “curtir” apresenta maior participação dos usuários, analisam-se as ações de informações do eleitorado a partir das curtidas em cada categoria de postagem para verificar quais os tipos de publicação atraíam maior atenção dos usuários (Figura 2).

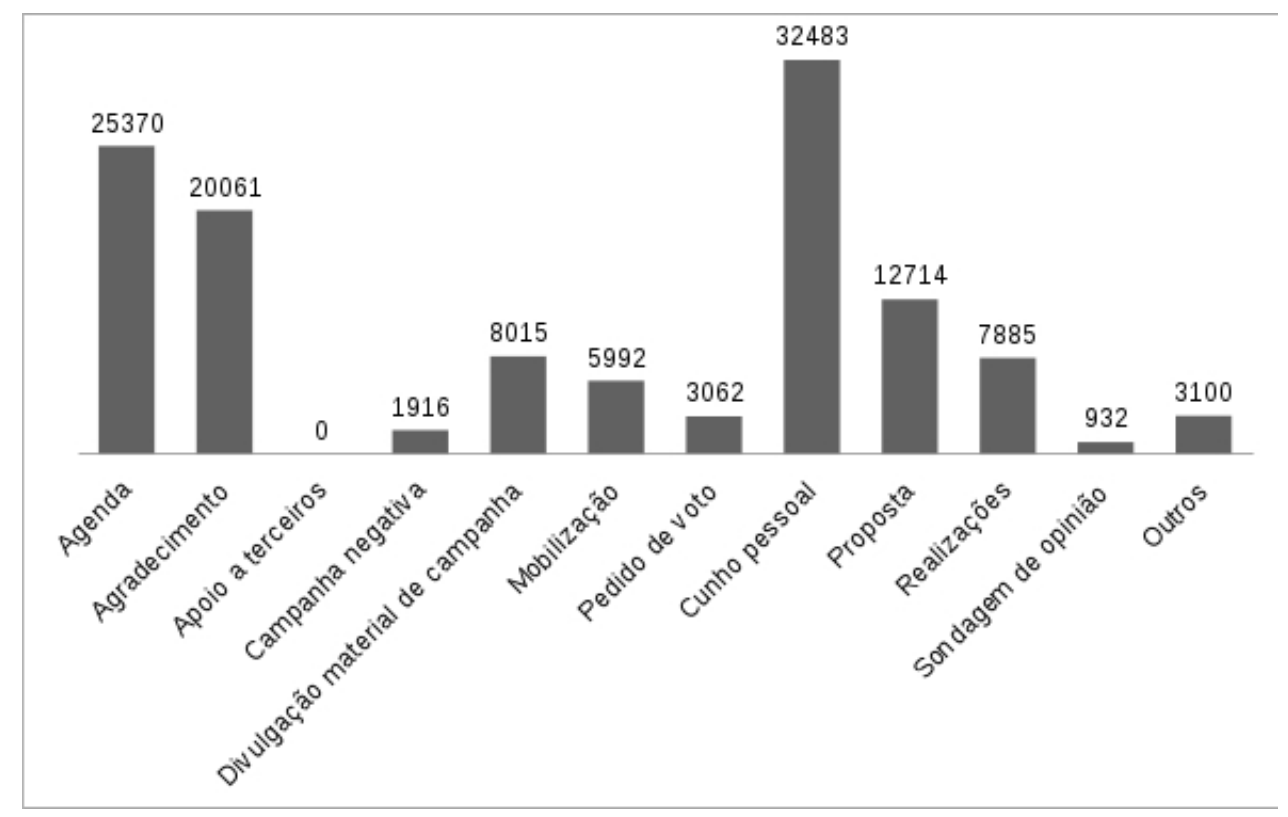

Figura 2. Total de curtidas por categoria na fanpage do candidato Rui Palmeira

Fonte: Dados da pesquisa (2016).

Apesar do período eleitoral, o tipo de postagem que mais obteve interações através de curtidas foram as Postagens de Cunho Pessoal (Figura 6), em que o candidato à prefeitura de Maceió publica sobre sua vida privada e momentos com sua família. C. L. S. Pereira (2013, p. 134) entende que a publicação de mensagens de cunho pessoal possibilitou a identificação do eleitorado com o agente político e tem a função de seduzir os eleitores, não de criar um ambiente de participação política. Em seguida, as postagens que mais obtiveram curtidas foram as referentes à Agenda e Agradecimentos do candidato, forma que o candidato encontrou de se manter presente nas mídias sociais, compartilhando compromissos de sua agenda de candidato e agradecendo o apoio demonstrado pelo povo para sua campanha durante a execução desses compromissos.

As postagens com propostas, realizações e divulgação de material de campanha, observando-se que o candidato era prefeito em exercício durante a candidatura, apresentaram-se com clara intenção de fortalecer o sentido de continuidade para a população, mostrando o que foi feito e o que seria realizado após a eleição, atraindo números intermediários de curtidas quanto comparadas com outras categoriais. Cabe ressaltar, que as postagens referentes à mobilização ou sondagem de opinião, categoria esta que teve menor número de curtidas, se caracterizam como postagens voltadas a chamar os seguidores a participar da campanha de forma atuante que, no entanto, não fazem parte das postagens que obtiveram maior interação através das curtidas. Estas apresentam número relativamente baixo no comparativo a outros tipos de postagens. Ao contrário do que pode ser pressupor, as postagens com referência a campanhas negativas para outros candidatos não apresentaram também um alto índice de curtidas, subentendendo-se que não são o tipo de postagens que dão ibope positivo à abordagem ou postura do candidato.

As mensagens categorizadas como Agenda do Candidato (Figura 3) consistem em publicações sobre eventos que o candidato participou, está participando ou participará, e têm o intuito de manter os eleitores a par das suas atividades. Chaia e Teixeira (2004, p. 61), apontam que pela agenda política é possível observar "o andamento da campanha eleitoral de cada candidato, [...] associar seu ritmo e força, pois uma agenda cheia demonstra que o candidato está com uma campanha bem estruturada e com uma grande receptividade por parte do eleitorado". 
Hoje estive reunido com os conselheiros tutelares de Maceió. Conversamos sobre os avanços que tivemos na assistêncial social em Maceió nos últimos anos, principalmente sobre a ampliação da rede de cobertura dos conselhos tutelares e o importante serviço de proteção à criança e ao adolescente que eles exercem. Muito bom contar com o apoio de todos! \#VamosEmFrente

Figura 3. Categoria Agenda - candidato Rui Palmeira Fonte: Dados da pesquisa (2016).

A categoria de Agradecimento/Cumprimento (Fig. 4.a) contempla as postagens com características saudação aos eleitores, agradecendo a participação em algum momento da campanha, por exemplo, uma passeata em determinado bairro. C. L. S. Pereira (2013, p. 137) destaca esta categoria enquanto estratégia de aproximação do eleitorado não somente pela argumentação racional, mas também pelo diálogo com a subjetividade dos eleitores-seguidores.
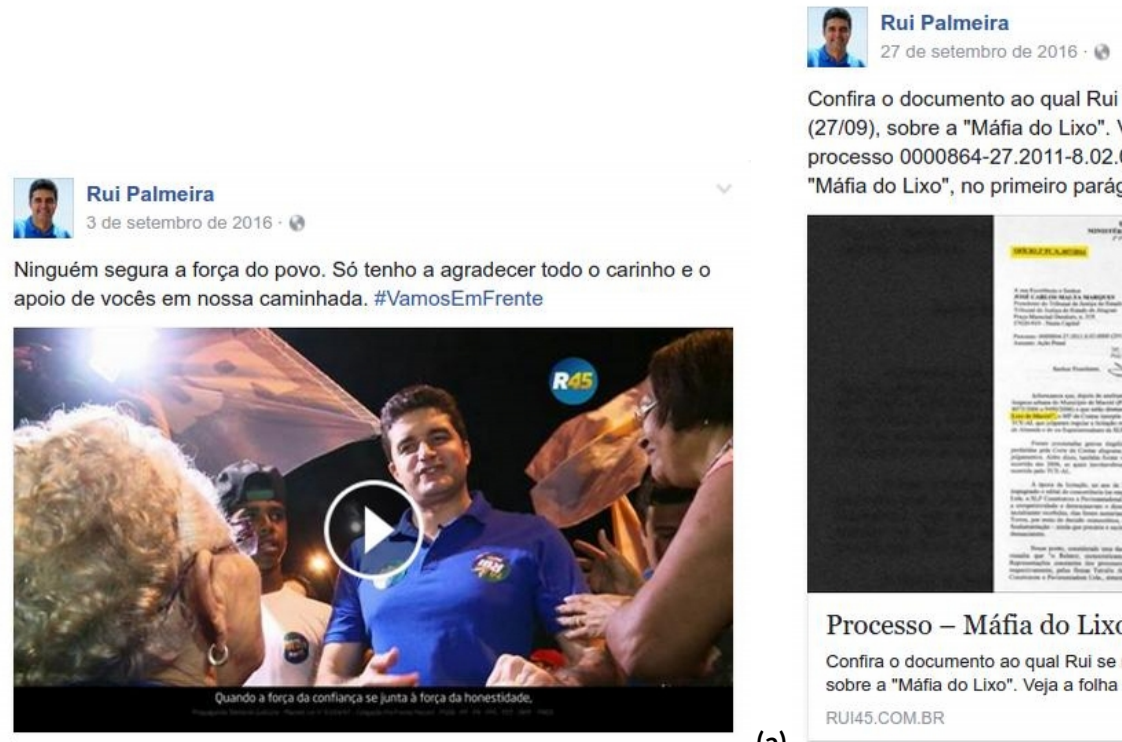

Confira o documento ao qual Rui se referiu, no debate da TV Ponta Verde (27/09), sobre a "Máfia do Lixo". Veja a folha 1.775 da peça que faz parte do processo 0000864-27.2011-8.02.0000 (2011.001386-7). Lá tem escrito "Máfia do Lixo", no primeiro parágrafo. \#EquipeRui
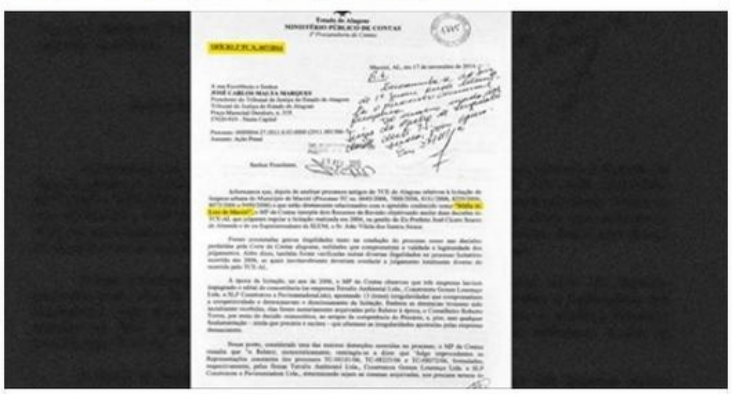

Processo - Máfia do Lixo

Confira o documento ao qual Rui se referiu, no debate da TV Ponte Verde (27/09) sobre a "Máfia do Lixo". Veja a folha 1.775 da peça que faz parte do process

(a) RU145.COM.BR

Figura 4. Categorias de postagens do candidato Rui Palmeira: (a) Agradecimento/Cumprimento; (b) Campanha Negativa. Fonte: Dados da pesquisa (2016).

As postagens referentes a críticas ou ataque a adversários foram categorizadas como Campanha Negativa (Fig. 4.b). A partir destas postagens, nota-se que os candidatos costumam levar para as mídias sociais o diálogo iniciado durante algum debate ou comercial eleitoral. Para Aggio (2011), "ainda que velados ou camuflados [...] ataques aos adversários, ao governo e aos partidos foram registrados como esforço para medir o nível de campanha negativa”.

19. Rui Palmeira 5 de setembro de $2016 \cdot 0$

O povo tá comparando porque os números não mentem: fizemos mais pela iluminação! Tá tudo explicado no programa de hoje.

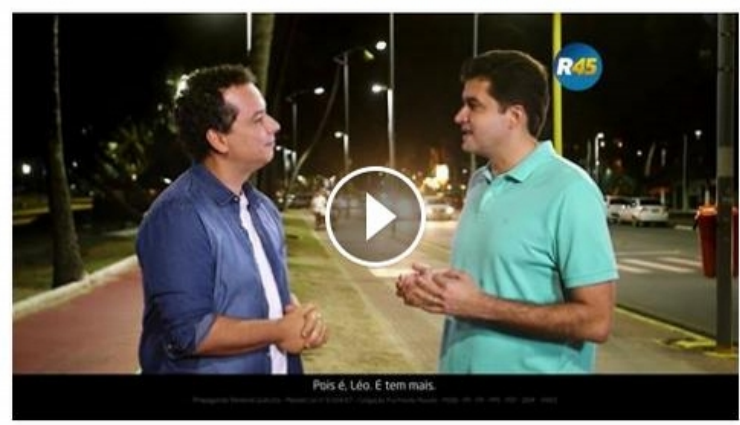

7. Rui Palmeira atualizou a foto da capa dele

Hoje estarei na Ponta Grossa! A concentração acontecerá na Praça Moleque Namorador, a partir das $19 \mathrm{~h}$. Convido vocês a virem caminhar com (a)

a gente! \#VamosEmFrente

Figura 5. Categorias de postagens do candidato Rui Palmeira: (a) Divulgação Material de Campanha; (b) Mobilização. Fonte: Dados da pesquisa (2016).

Sobre Divulgação de Material de Campanha (Fig. 5.a), Aggio (2011), define como característica “a utilização de links internos ou externos à campanha. Sua finalidade é divulgar, sem menção a qualquer demanda por parte 
dos internautas". Nota-se uma presença forte do que se conhece como marketing na campanha, no qual através de imagens com características de folders e panfletos ou vídeos comerciais, com propaganda eleitoral, exibidos também em redes de televisão. Tais postagens buscavam somente promover e fazer o candidato conhecido perante os eleitores.

Mobilizar pode ser considerado de maneira geral como forma ou efeito "incitar à participação", logo, nesta categoria, foram classificadas aquelas postagens que chamavam os eleitores-seguidores à participação na campanha de forma ativa, através de solicitações de colaboração em momentos de divulgação da campanha, ou convites para passeatas e/ou carreatas que seriam realizadas posteriormente, dentre outros. Para Aggio (2011, p. 10), a categoria Mobilização (Fig. 5.b) "consiste em publicações, com ou sem links, para que os eleitores se mobilizem em algum tipo de atividade de campanha, desde as presenciais até aquelas circunscritas aos ambientes digitais, como o 'twitaço"'.

As postagens categorizadas como Pedido de Voto (Fig. 6.a) são aquelas em que o candidato exterioriza o pedido de forma direta, já a categoria Sondagem de Opinião, de acordo com Aggio (2011), "permite sustentar estratégias retóricas que fomentem a mobilização dos eleitores em prol de maior crescimento da campanha", nesta categoria estão inseridas aquelas postagens em que o candidato tanto apresenta resultados de alguma pesquisa, quanto realiza a próprio questionamento sobre quem o seguidor irá votar, objetivando confirmar a predisposição daqueles que estão em sua página se tornarem seus eleitores.

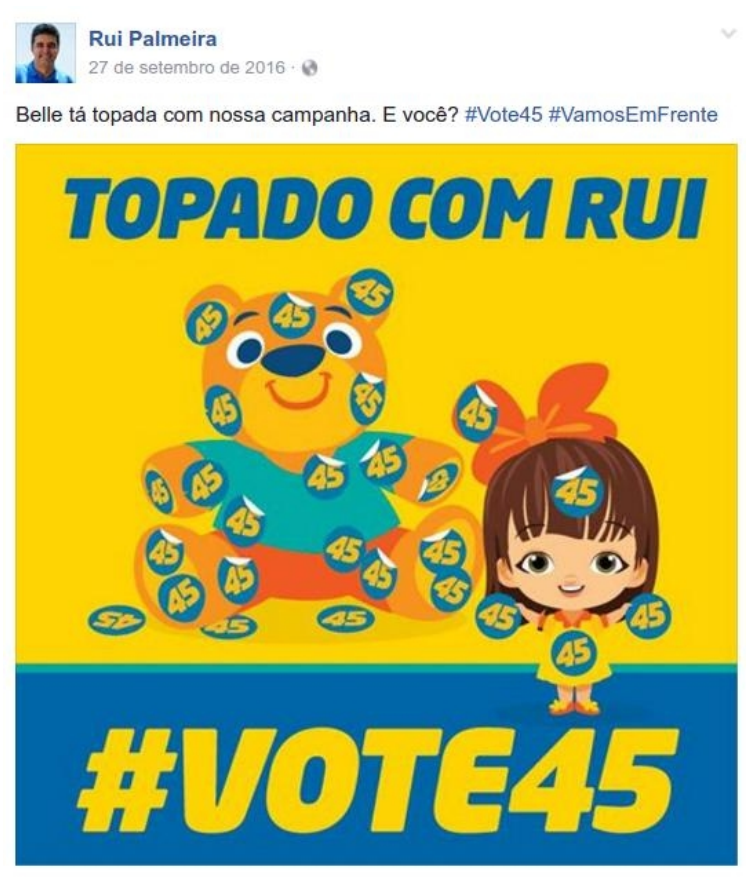

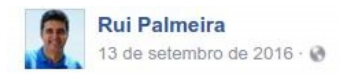

Comemorando mais um ano de vida ao lado das minhas meninas!

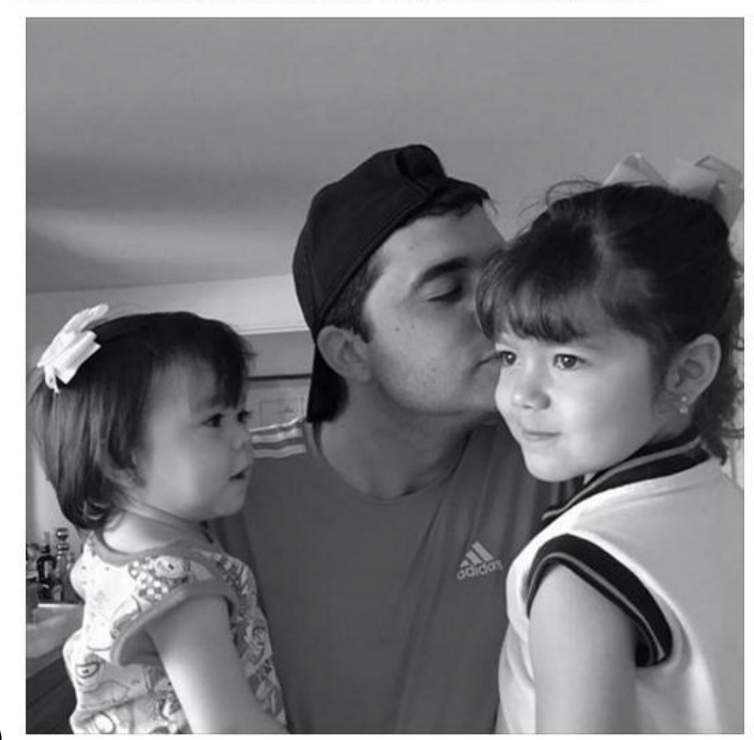

(b)

Figura 6. Categorias de postagens do candidato Rui Palmeira: (a) Pedido de Voto e Sondagem de Opinião; (b) Postagem de Cunho Pessoal. Fonte: Dados da pesquisa (2016).

De acordo com C. L. S. Pereira (2013, p. 41) “os meios de comunicação tendem a privilegiar as características de quem melhor souber se apropriar deles, no sentido do domínio de técnicas da mídia”, assim, em algumas postagens o candidato acabou por revelar momentos de seu cotidiano, enquanto estratégia de campanha, objetivando que as pessoas o enxergassem enquanto filho, marido e pai, e não somente como candidato (Fig. 6.b). Foram classificadas aqui postagens que não apresentavam ligação direta com a campanha em andamento.

A categoria Propostas (Fig. 7.a) constitui-se de postagens que contemplam soluções para possíveis necessidades dos eleitores ou comunidades. A proposta destaca-se enquanto "elemento fundamental dos discursos de campanha e um dos indicadores mais importantes para a diferenciação dos projetos políticos representados pelas candidaturas" (Aggio, 2011), posto que é através das propostas de cada candidato que torna-se possível compreender o que ele pretende realizar durante seu governo caso seja eleito. Essas propostas tornam-se elos entre o candidato e a possível conquista de afinidade dos eleitores ao plano de governo.

A categoria Realizações (Fig. 7.b) contempla "publicações que se referem à atuação política pregressa dos candidatos” (Aggio, 2011), ou seja, aquelas postagens que retratam ações já realizadas na vida política do candidato antes sua candidatura. Através dessas postagens o candidato apresenta o que já realizou e com isso reforça o objetivo de angariar votos para continuar realizando novas conquistas para os eleitores-seguidores.

Na categoria Outros (Fig. 7.c), foram enquadradas as publicações que não se encaixam nas categorias trabalhadas anteriormente por não ter uma mensagem objetivamente clara dentro dos padrões de campanha online. 


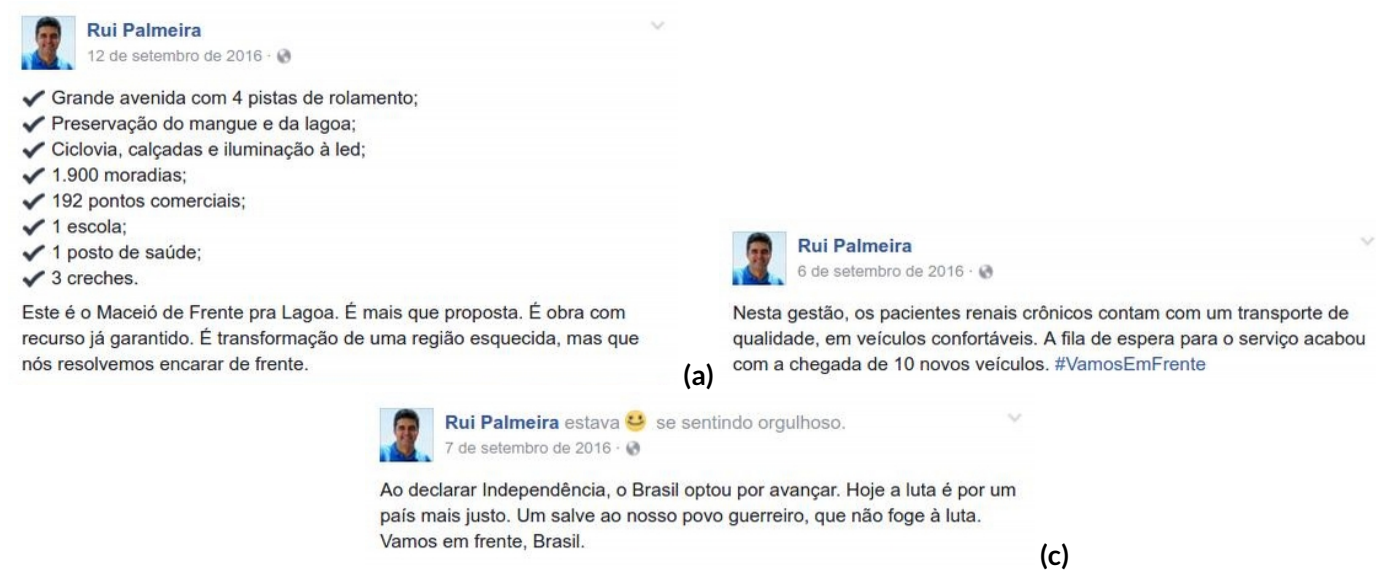

Figura 7. Categorias de postagens do candidato Rui Palmeira: (a) Propostas; (b) Realizações; (c) Outros. Fonte: Dados da pesquisa (2016).

Aggio (2011) aponta esse tipo de publicação como postagens triviais. No caso, da Figura 7.c o candidato faz menção a uma data comemorativa, no dia da independência, sem dirigir-se diretamente a população e com conteúdo que não está diretamente ligado à campanha.

\section{CONSIDERAÇÕES FINAIS}

Na busca por novos espaços para discussão de temas pertinentes à sociedade encontram, no Facebook, o espaço e as características tidas como ideais para aglomeração e consolidação de pautas sociais. É válido lembrar que muitos movimentos atualmente se iniciam dentro de mídias sociais, como o Facebook, ganham forma nas interações e se exteriorizam. Dos exemplos mais significativos, pode ser mencionada a mobilização e participação política de uma considerável parte do povo egípcio pelas redes sociais ${ }^{2}$ até à queda de Mubarak, até então presidente pelos últimos 30 anos. Conhecida como "Primavera Árabe", tal movimento, de acordo com N. B. Pereira (2013), marca a participação política na contemporaneidade no contexto da globalização e da crise de identidades que perpassam as esferas constitutivas da estabilidade ao corpus social. A autora ressalta o papel das mídias sociais na reconfiguração da participação no ciberespaço na formação das comunidades virtuais, que operam com base em laços identitários e potencializam a capacidade de mobilização cívica.

Pode-se afirmar que até para segmentos tão tradicionais da sociedade, como é o caso da política, novos espaços de discussão se fazem necessários, posto que é preciso apresentar suas ideias onde a sociedade se encontra atualmente e, nesse caso, boa parte se encontra nos espaços Web 2.0.

Na realidade apresentada na presente pesquisa, mais precisamente na cidade de Maceió, onde foi feito o estudo, pode-se concluir que esses espaços começaram a ser ocupados e tratados com a devida relevância e já funcionam como dispositivos de mediação da informação cumprindo o papel de aproximação entre candidatos e eleitores. Isso pode ser verificado pelo número de interações identificado pela diversificação das categorias de postagens, bem como pela preocupação em produzir e promover conteúdo para seus possíveis eleitores. Isto demonstra que o candidato em questão conseguiu compreender algumas premissas da Web 2.0, tais como a interação e a colaboração com o que foi produzido. Contudo, a responsividade do candidato e interação direta com os eleitores pela ferramenta de mídia, conforme apresentada pelos dados, se configura como um desafio.

\footnotetext{
${ }^{2}$ Ver matéria do Jornal O Globo: “Redes sociais desempenharam papel fundamental na queda de Mubarak, afirmam especialistas”, por Rennan Setti (Setti, 2011).
} 


\section{REFERÊNCIAS}

Aggio, C. (2011). As campanhas políticas no Twitter: uma análise do padrão de comunicação política dos três principais candidatos à presidência do Brasil em 2010. In IV Encontro da Associação Brasileira dos Pesquisadores em Comunicação e Política. Rio de Janeiro. Recuperado de http://www.compolitica.org/home/wp-content/uploads/ 2011/03/AGGIO-Camilo.pdf

Almeida Júnior, O. F. (2009, jan./dez.). Mediação da informação e múltiplas linguagens. Pesq. bras. Ci. Inf., 2(1), 89 103. Recuperado de http://inseer.ibict.br/ancib/index.php/ tpbci/article/viewFile/17/39

Amaral, M. (2010). Internet e participação política: o uso da internet pelo cidadão. Cadernos de Ciências Sociais Aplicadas, 7(9), 100 - 124. Recuperado de http://periodicos.uesb.br/ index.php/cadernosdeciencias/article/viewFile/882/889

Araújo, R. F. (2014a). Atores e ações de informação em redes sociais na internet: pensando os regimes de informação em ambientes digitais. DataGramaZero, 15(3), 9. doi: http://10.6084/m9.figshare.3383263

Araújo, R. F. (2014b). Mediação da informação e participação política na web social em períodos eleitorais. In Encontro Nacional de Pesquisa em Ciência da Informação (v. 15, p. 1457 1477). Belo Horizonte: Ancib/PPGCI/ECI/UFMG. Recuperado de http://200.20.0.78/repositorios/handle/123456789/2661

Araújo, R. F. (2016). O Twitter como dispositivo de mediação da informação em períodos eleitorais. In Seminário em Ciência da Informação: Fenômenos emergentes na Ciência da Informação (p. 500-511). Recuperado de http://www.uel.br/eventos/cinf/index.php/ secin2016/secin2016/paper/viewFile/281/142

Araújo, R. F., \& Pereira, B. C. (2013). O Twitter como ferramenta de mediação cívica: interatividade e conversação nas eleições municipais de Maceió. In Congresso da Associação Brasileira de Pesquisadores em Comunicação e Política (p. 1 - 20). Recuperado de http:// www.compolitica.org/home/wp-content/uploads/2013/05/ GT04-Internet-e-politica-RonaldoFerreiraDeAraujo.pdf

Barros, A. T., Bernardes, C. B., \& Sathler, M. R. (2016). Faces partidárias na esfera virtual: a atuação política das lideranças da Câmara dos Deputados no Facebook. In $X$ Encontro anual da ABCP. Recuperado de http://www .encontroabcp2016.cienciapolitica.org.br/resources/anais/ 5/1468760331_ARQUIVO_Barros,BernardeseRehbein.pdf

Cervi, E. U., \& Massuchin, M. G. (2011, ago.). O uso do Twitter nas eleições de 2010: o microblog nas campanhas dos principais candidatos ao governo do Paraná. Contemporanea: comunicação e cultura, 9(2), 319 - 334. doi: 10.9771/18099386contemporanea.v9i2.5083

Chaia, V., \& Teixeira, M. A. (2004). Telejornalismo e radiojornalismo nas eleições de 2000 e 2002 (Projeto temático: mídia, campanha eleitoral e comportamento político em São Paulo). Recuperado de http://www.pucsp.br/neamp/downloads/ relatorio_final_midia_campanha_eleitoral_comportamento _politico_SAO_PAULO.pdf

Cossetti, M. C. (2016). Facebook revela dados do Brasil na CPBR9 e WhatsApp vira ZapZap. TechTudo. Recuperado de http://www.techtudo.com.br/noticias/noticia/2016/01/ facebook-revela-dados-do-brasil-na-cpbr9-e-whatsapp -vira-zapzap.html

Fragoso, S., Recuero, R., \& Amaral, A. (2012). Teoria fundamentada. In Métodos de pesquisa para internet. Porto Alegre:
Sulina.

G1. (2016, 30 de set.). IBOPE votos válidos: Rui Palmeira tem 46\%, Cícero Almeida, 26\%, e JHC, 23\%. G1 Alagoas. Recuperado de http://glo.bo/2du3N3W

Gil, A. C. (2002). Como elaborar projetos de pesquisa? (4a. ed.). São Paulo: Atlas.

Gruzd, A., et al. (2017). Netlytic. Recuperado em 19 set. 2017, de https://netlytic.org/

Pereira, C. L. S. (2013). Redes sociais como palco da participação política no Egito. In IX Encontro Nacional de História da Mídia. Ouro Preto: ALCAR/UFOP. Recuperado de http://www.ufrgs.br/alcar/encontros-nacionais-1/9o -encontro-2013/artigos/gt-historia-da-midia-digital/redes -sociais-como-palco-da-participacao-politica-no-egito

Pereira, N. B. (2013). Sob o piado do Twitter: o novo tom das campanhas eleitorais com a difusão da internet no Brasil (Dissertação de mestrado, Pontifícia Universidade Católica de São Paulo, São Paulo). Recuperado de https://sapientia.pucsp.br/bitstream/handle/3481/1/ Natasha\%20Bachini\%20Pereira.pdf

Recuero, R. (2011). Redes Sociais na Internet (2a. ed.). Porto Alegre: Sulina.

Setti, R. (2011, 04 de nov.). Redes sociais desempenharam papel fundamental na queda de Mubarak, afirmam especialistas. O Globo. Recuperado de https://glo.bo/2xOhl80

Silva, A. P., \& Gonzales, W. (2016). Facebook e participação política: o que dizem os jovens do \#ocupaalemão. Horizontes, 34(1), 159 - 172. Recuperado de https://revistahorizontes .usf.edu.br/horizontes/article/view/337

Silva, R. B. (2014, jan./jun.). Mídias sociais e política: os partidos no Facebook. Alceu, 14(28), 202 - 223. Recuperado de http://revistaalceu.com.puc-rio.br/media/alceu\%2028\% 20-\%20202-223.pdf

Zuckerberg, M. (2017, fev.). Facebook community update. Recuperado de https://www.facebook.com/ photo.php?fbid=10103472646530311 \&set=a. 529237706231 .2034669.4\&type $=3$ \&permPage $=1$

Como citar este artigo (APA):

Araujo, R. F., Santos, S. R. O. \& Bento, J. M. (2017). Mediação da informação e comunicação política no Facebook: desempenho do candidato Rui Palmeira à Prefeitura de Maceió em 2016. AtoZ: novas práticas em informação e conhecimento, 6(1), 17 - 25. Recuperado de: http://dx.doi.org/10.5380/atoz.v6i1.54543 